\title{
16th International Conference on Microscopy of Semiconducting Materials Issues Call for Papers \\ www.rms.org.uk/MSMXVI
}

The 16th International Conference on Microscopy of Semiconducting Materials will be held at Oxford University, United Kingdom, on March 17-20, 2009. The conference, chaired by John Hutchison and Pete Nellist (Oxford Univ.) with Thomas Walther and Tony Cullis (Sheffield Univ.), will focus on the latest developments in the study of the structural and electrical properties of semiconductors by the application of transmission and scanning electron microscopy (SEM), scanning probe microscopy (SPM), and x-ray-based methods.

Conference sessions will concentrate on key topics including state-of-the-art studies in high-resolution imaging and analytical electron microscopy, advanced SEM, SPM and focused ion beam applications, novel epitaxial layer phenomena, the properties of quantum nanostructures, III-nitride developments, GeSi/Si for advanced devices, metal-semiconductor contacts and silicides and the important effects of critical device processing treatments.

Invited speakers include D. Bell (Harvard Univ.), "Developments in $\mathrm{He}^{+}$ Ion Microscopy"; E. Carlino (TASC, Trieste), "Z-Contrast of Nanostructures"; D.J. Cherns (Bristol Univ.), "GaN Nanorod Devices"; A. Craven (Glasgow Univ.), "STEM-EELS of High- $k$ Dielectrics"; R. Dunin-Borkowski (Technical Univ. of Denmark), "Electron Holography of Doped Semiconductors"; D. Gerthsen (Karlsruhe Univ.), "In Incorporation in InAs Nanostructures"; F. Glas (LPN, Marcoussis), "Studies of III-V Nanowires"; M. Hecker (AMD Dresden), "Strain Analysis for CMOS Technology"; R. Hull (Rensselaer Institute, Troy),
"Templated Assembly of Nanostructures"; C. Kisielowski (NCEM, Berkeley), "Imaging Single Light Atoms"; S. Kodambaka (UCLA), "Au-Catalyzed Growth of Si Nanowires"; S. Molina (Cadiz Univ.), "HREM of Quantum Dots and Wires"; S. Tsukamoto (Anan College of Technology), "In situ STM During MBE Growth"; and W. Vandervorst (IMEC, Leuven), "Nanoscale Analysis of Planar and 3D Si Structures."

The abstract deadline is December 2, 2008. Conference proceedings will be published. For further details and information on abstract submission and registration, access the conference Web site at www.rms.org.uk/MSMXVI or e-mail to victoria@rms.org.uk.
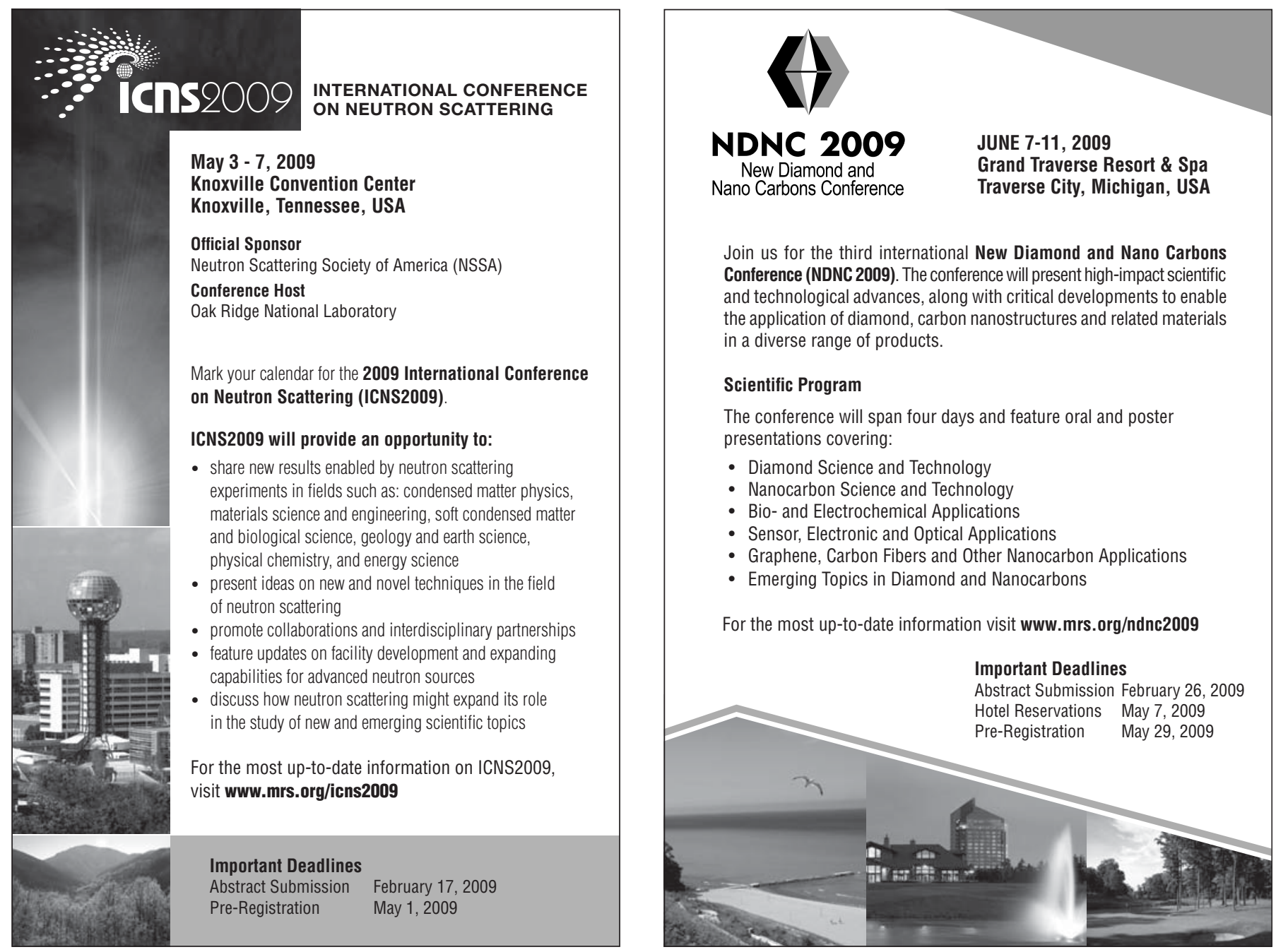